\title{
Avaliação Quanti-Qualitativa do Ar Interior de Uma Biblioteca Pública do Município de Cuiabá-MT
}

\section{Quanti-Qualitative Assessment of Indoor Air of a Public Library of the City of Cuiabá}

\author{
${ }^{1}$ Flaviane de Morais Campos, ${ }^{2}$ Rossean Golin, ${ }^{3}$ Frederico César Caixeta, ${ }^{4}$ Luciana Sanches, ${ }^{5}$ Danila Soares \\ Caixeta \\ ${ }^{1}$ Graduada em Engenharia Sanitária e Ambiental, Universidade Federal de Mato Grosso - UFMT \\ (flavi.morais@ hotmail.com) \\ 2 Técnica do Laboratório de Microbiologia Sanitária e Ambiental, Departamento de Engenharia \\ Sanitária e Ambiental - DESA, Faculdade de Engenharia, Arquitetura e Urbanismo - FAET - UFMT \\ (golin.rossean@gmail.com) \\ ${ }^{3}$ Graduando em Medicina - Universidade de Cuiabá - UNIC (fredcaixeta@ gmail.com) \\ ${ }^{4}$ Professora Pesquisadora no Programa de Pós Graduação em Física Ambiental e no DESA- FAET- \\ UFMT (lsanches@hotmail.com) \\ ${ }^{5}$ Professora Pesquisadora no Programa de Pós Graduação em Recursos Hídricos - PPGRH e no \\ DESA-UFMT (danilacaixeta@gmail.com)
}

\begin{abstract}
RESUMO: A qualidade do ar interior tem ganhado especial atenção nas últimas décadas, devido ao elevado tempo de permanência dos ocupantes nesses ambientes e consequentemente maior exposição a poluentes patogênicos. Objetivou-se com essa pesquisa avaliar a qualidade microbiológica do ar interior de uma biblioteca situada no município de Cuiabá-MT, utilizando o Método de Sedimentação Espontânea e Impactação sobre meio de cultura sólido. Em suma, os resultados obtidos para temperatura e umidade, na maioria dos pontos amostrados e período de coleta, mostraram fora dos padrões estabelecidos pela legislação em vigência. Em relação a qualidade bacteriológica foi constatado que para ambas metodologias utilizadas, 97\% dos isolados apresentaramse como Gram positivas. Por outro lado, na contagem fúngica pode-se observar que para relação Interior/Exterior na maioria dos pontos amostrados houve crescimento superior ao recomendado. Dentre os diversos fungos isolados, foi constatada a presença de Aspergillussp. ePenicillium sp. Assim, em locais de aprendizagem e desenvolvimento intelectual, social e pessoal como a biblioteca, a necessidade da implantação de medidas de prevenção e proteção de todos os seus freqüentadores no que se refere a problemática da Qualidade do Ar Interior.
\end{abstract}

Palavras-chave: Biblioteca, Microrganismos, Saúde pública.

\begin{abstract}
The indoor air quality has gained attention in recent decades, due to the high residence time of the occupants in these environments and consequently greater exposure to pathogenic pollutants. The objective of this research was to evaluate the microbiological quality of the indoor air of a library located in the city of Cuiaba-MT, using the spontaneous sedimentation method and impaction on solid medium. In short, the results for temperature and humidity in most sampling sites and sampling period, showed off the standards established by legislation in force. Regarding the bacteriological quality it was found that for both methods used, $97 \%$ of the isolates were presented as Gram positive. On the other hand, in fungal count can be observed that compared to Indoor / Outdoor in most of the points was higher than the recommended growth. Among the various fungi isolated, it was found the presence of Aspergillus sp. and Penicillium sp. Thus, in places of learning and intellectual development, social and personal as the library, the need to implement preventive measures and protection of all its patrons as regards the issue of Indoor Air Quality.
\end{abstract}

Keywords: Library, Microorganisms, Public health.

\section{INTRODUÇÃO}

Nas últimas décadas, houve um crescimento populacional e consequentemente uma aceleração no processo de urbanização. Indubitavelmente, tal fato, tem conduzido a alterações na qualidade do ar, principalmente em cidades onde há maiores aglomerações de indivíduos.

Sobretudo, Qualidade do Ar Interior (QAI) tem se tornado um tema de grande relevância mundial, pois devido as mudanças no estilo de vida, as pessoas permanecem em média $80 \%$ - $90 \%$ em ambientes interior climatizados artificialmente, consumindo 
Campos, F. M.; Golin, R.; Caixeta, F. C.; Sanches, L.; Caixeta, D. S.; Avaliação Quanti-Qualitativa do Ar Interior de Uma Biblioteca Pública do Município de Cuiabá-MT. E\&S - Engineering and Science, (2017), 6:1.

aproximadamente $14 \mathrm{~m}^{3}$ de ar por dia (HAYLEEYESUS \& MANAYE2014). Contudo, o número de indivíduos por área, atividades humanas, equipamentos, temperatura, umidade, ventilação, local e estrutura da edificação, design, dentre outros fatores contribuem para o crescimento e proliferação de microrganismos e outras micropartículas, em um ambiente interior.

As bibliotecas, por sua vez, são locais ideais para o crescimento de microrganismos, pois agrupam num mesmo espaço uma grande quantidade de matéria orgânica, como papel, cola de amido, couro e pano. Karbowska-Berentet al. (2011), mencionam que livros e outros materiais de arquivo são ricos reservatórios de nutrientes, principalmente celulose que é o principal componente do papel e proteínas que estão presentes na cola e adesivos usados na manufatura do produto. Esses nutrientes estimulam o crescimento de grupos específicos de microrganismos, dentre eles os fungos que exibem propriedades celulolítica (Trichoderma, Penicillium, Botrytis, Chaetomium, Stemphyliume Alternaria), proteolítica (Mucor, Aureobasidum, Chaetomium, Trichoderma, Verticillium e Epicoccum) e lipolítica (Paecilomyces).

Ademais, levantamento realizado por Osimaniet al. (2016), apontam que a contaminação do ar interior por bactérias é predominantemente representada por membros atribuídos aos gêneros Aeromonas, Bacillus, Micrococcus, Kocuria, Nocardia, Pseudomonas e Staphylococcus, enquanto que fungos mais comumente identificados pertencem aos gêneros Alternaria, Aspergillus, Chaetomium, Cladosporium, Mucor, Penicillium e Stachybotris.

$\mathrm{Na}$ literatura, há vários estudos que investigam a microbiota fúngica e bacteriana em bibliotecas públicas (GAMBALE et al. 1993, KARBOWSKA-BERENT et al. 2011; PANTOJA et al. 2012; MICHELUZ et al. 2015; SKÓRA et al. 2015).

Quando presentes, estes contaminantes podem afetar direta ou indiretamente a qualidade de vida dos indivíduos. Segundo Mendes et al. (2015) micropartículas com diâmetro menor $2,5 \mu \mathrm{m}$ podem penetrar profundamente no tecido pulmonar ocasionando redução na função do pulmão, inflamação dos alvéolos pulmonares, doenças respiratórias diversas, efeitos cardiovasculares adversos, aumento da prevalência de Doença Pulmonar Obstrutiva Crónica, e causar o stress oxidativo do DNA. Por outro lado, de modo geral, as principais doenças associadas a presença de microrganismos são o Mal dos Legionários; a febre do umidificador (doença que se desenvolve a partir de exposições a toxinas de microrganismos, especialmente daqueles que crescem nos sistemas de ventilação dos edifícios); asma brônquica; pneumonite alérgica ou alveolite extrínseca; e pneumonia (SCHIRMER et al. 2011).

Por consequência, o estudo da qualidade do ar interior é de suma importância, pois permite averiguar as possíveis fontes de contaminação e consequentemente aprimorar as estratégias para controlar e prevenir as doenças relacionadas a situações adversas dos ambientes interiores.

Objetivou-se com essa pesquisa avaliar quantitativamente fungos filamentosos e bactérias presentes em uma biblioteca pública localizada no município de Cuiabá-MT, utilizando o Método de Sedimentação Espontânea e Impactação sobre meio de cultura sólido.

\section{MATERIAL E MÉTODOS}

Área de estudo 
Campos, F. M.; Golin, R.; Caixeta, F. C.; Sanches, L.; Caixeta, D. S.; Avaliação Quanti-Qualitativa do Ar Interior de Uma Biblioteca Pública do Município de Cuiabá-MT. E\&S - Engineering and Science, (2017), 6:1.

O presente estudo foi realizado em uma biblioteca pública localizada no município de Cuiabá-MT. As amostras foram coletadas nos pontos de amostragem conforme citado abaixo e no meio externo, no período de maio a julho de 2012.

- $\quad$ Piso 1: Hemeroteca (P1).

- $\quad$ Piso 2: Acervos Amedecis (P8), Sala de leitura (P3), Sala de internet (P9) e Saguão (P2).

- $\quad$ Piso 3: Acervo de ciências humanas (P6), Acervo de exatas (P4 e P5) e Acervo de linguagens (P7).

As coletas foram realizadas utilizando-se de duas metodologias distintas, sendo: método de sedimentação espontânea e o método de impactação.

$\mathrm{Na}$ amostragem por sedimentação espontânea as placas foram expostas a uma altura de 1,5 metros do solo entre o espaço dos livros na superfície das estantes, durante o tempo de 15 minutos, contendo o meio de cultura Ágar Nutriente (Himedia) e Ágar Sabouraud Dextrose (Himedia), para isolamento de bactérias e fungos, respectivamente. Após a coleta as placas foram incubadas a $37^{\circ}$ por $24-48$ horas para crescimento bacteriano e 7 dias à temperatura de $25^{\circ} \mathrm{C}$ para crescimento de fungos. Para determinar a contagem em UFC $/ \mathrm{m}^{3}$, utilizou-se os cálculos propostos por Friberg et al. (1999).

Para o método de impactação, as coletas foram realizadas conforme recomendado pela RE/Anvisa $n^{\circ} 9$ de 2003, utilizando-se de umamostrador de ar modelo SAS - SUPE ISSO 100/180.Após 24 horas de incubação a $37^{\circ}$ para contagem de bactérias e 7 dias à temperatura de $25^{\circ} \mathrm{C}$ para fungos, o número total de $\mathrm{UFC} / \mathrm{m}^{3}$ de ar foi determinada, utilizando-se a tabela de conversão, conforme sugerido pelo fabricante do aparelho utilizado.

\section{Identificação das Bactérias e Fungos}

Para a identificação das bactérias e fungos foi observado os aspectos macroscópicos das colônias e aspectos microscópicos.

Colônias caracterizadas como bactérias foram isoladas e posteriormente realizado o processo de coloração de Gram. Após o processo de coloração de Gram, conforme protocolo do Laboratório de Microbiologia Sanitária e Ambiental - LAMSA, as lâminas foram analisadas em Microscópio Óptico da marca Opton, com objetiva 100 X.

A fim de se observar às estruturas microscópicas e identificar os gêneros fúngicos, foi adotada a Técnica do Microcultivo em Lâmina, utilizando Ágar Sabouraud Dextrose. Após o crescimento fúngico, foram preparadas lâminas aplicando-se o corante azul de metileno, e realizada a observação microscópica através do Microscópio Óptico da marca Opton, com objetiva $40 \mathrm{X}$.

\section{Medição de Temperatura e Umidade Relativa do Ar}

Para avaliação dos níveis de umidade relativa do ar e temperatura, utilizou-se do aparelho HOBO U12-012.

As coletas de temperatura e umidade relativa no mês de maio foram realizadas no período vespertino com início às 15:30 horas e término as 17:30 horas. Nas coletas dos meses de junho e julho as medições foram realizadas no período da manhã tendo início as 08:30 e término as 12:50. 
Campos, F. M.; Golin, R.; Caixeta, F. C.; Sanches, L.; Caixeta, D. S.; Avaliação Quanti-Qualitativa do Ar Interior de Uma Biblioteca Pública do Município de Cuiabá-MT. E\&S - Engineering and Science, (2017), 6:1.

\section{RESULTADOS E DISCUSSÕES}

\section{Temperatura e Umidade Relativa do Ar}

Os resultados da temperatura e umidade podem ser observados na Tabela1.

Tabela 1-Temperatura e umidade nos pontos de amostragem, no período de maio, junho e julho de 2012.

\begin{tabular}{ccccccc}
\hline $\begin{array}{c}\text { Pontos de } \\
\text { Coleta }\end{array}$ & \multicolumn{2}{c}{ Maio } & \multicolumn{2}{c}{ Junho } & \multicolumn{2}{l}{ Julho } \\
\cline { 2 - 7 } & $\mathbf{T}$ & $\mathbf{U R}$ & $\mathbf{T}$ & $\mathbf{U R}$ & $\mathbf{T}$ & UR(\%) \\
& $\left({ }^{\mathbf{o}} \mathbf{C}\right)$ & $(\boldsymbol{\%})$ & $\mathbf{(} \mathbf{C})$ & $(\boldsymbol{\%})$ & $\left({ }^{\mathbf{o}} \mathbf{C}\right)$ & \\
\hline Piso 1: P1 & 21,43 & 76,04 & 22,46 & 78,77 & 22,49 & 26,00 \\
Piso 2: P2 & 22,02 & 76,19 & 22,72 & 78,70 & 22,63 & 25,97 \\
Piso 2: P3 & 20,24 & 76,57 & 22,81 & 78,59 & 22,76 & 25,92 \\
Piso 3: P4 & 16,06 & 76,11 & 23,03 & 78,50 & 22,90 & 25,87 \\
Piso 3: P5 & 19,27 & 76,43 & 23,07 & 78,41 & 22,90 & 25,87 \\
Piso 3: P6 & 21,02 & 76,40 & 23,12 & 78,31 & 22,96 & 24,22 \\
Piso 3: P7 & 21,02 & 76,70 & 23,17 & 78,24 & 23,06 & 25,80 \\
Piso 2: P8 & 21,63 & 76,28 & 23,63 & 74,62 & 23,10 & 25,77 \\
Piso 2: P9 & 19,13 & 76,30 & 23,41 & 78,09 & 23,15 & 25,74 \\
Externo & 22,73 & 75,98 & 23,80 & 25,68 & 23,20 & 25,71 \\
\hline
\end{tabular}

A RE/ANVISA $n^{\circ} 9$ de 2003 estipula uma faixa recomendável de temperatura visando o conforto térmico humano, sendo adotado para o verão temperatura entre $23^{\circ} \mathrm{C}$ e $26^{\circ} \mathrm{C}$ e, para o inverno, entre $20^{\circ} \mathrm{C}$ e $22^{\circ} \mathrm{C}$. Salienta-se que, nessa pesquisa adotou-se para a temperatura e umidade valores referentes ao inverno, uma vez que nos meses de maio e junho a estação é outono e julho inverno.

Considerando essa referência, nota-se que, no mês de maio a maior temperatura foi no ponto $\mathrm{P} 2\left(22,02^{\circ} \mathrm{C}\right)$ e a menor no ponto $\mathrm{P} 4\left(16,06^{\circ} \mathrm{C}\right)$, enquanto que no mês de junho a maior temperatura foi no P8 $(23,63)$ e menor no P1 $(22,46)$. Ademais no mês de julho, todos os pontos excederam a temperatura de $22^{\circ} \mathrm{C}$ estabelecido pela resolução supracitada.

Vale ressaltar, que nos meses de junho e julho as coletas foram feitas com os aparelhos de ar condicionado desligados, apenas no P3, o aparelho estava em funcionamento, no entanto, essa temperatura encontra se em desacordo com o estabelecido.

Em relação aos valores de umidade relativa do ar recomendados pela RE/ANVISA ${ }^{\circ} 9$ de 2003, a mesma menciona que os valores sejam mantidos na faixa de $40 \%$ a $65 \%$ no verão e no inverno entre $35 \%$ a $65 \%$, considerando a umidade referente ao inverno, nota-se que nos meses de maio e junho a umidade relativa do ar de todos os pontos excederam o valor máximo estabelecido, enquanto que no mês de julho todos os pontos apresentaram valores abaixo do permitido.

De fato, a umidade elevada e a ventilação deficiente propiciam o desenvolvimento de agentes biológicos no ar interior, além de provocar a degradação dos materiais, o que constitui outro fator de poluição do ar interior e tem sido considerado o principal fator de risco para saúde dos ocupantes.

Silva Filho et al. (2004) recomenda em seu manual de conservação de acervos bibliográficos, valores adequados de temperatura e umidade relativa, entre outras variáveis, para evitar a deterioração do material. As faixas indicadas correspondem à manutenção da temperatura entre $19^{\circ} \mathrm{C}$ e $23^{\circ} \mathrm{C}$, e a umidade relativa entre $50 \%$ a $60 \%$, sendo o ideal $55 \%$. Tais valores corroboram as recomendações italianas (MiBAC 2001), onde as melhores condições para preservar os livros e produtos de papel é temperatura entre $19-24^{\circ} \mathrm{C}$ e umidade relativa entre $50-60 \%$. 
Campos, F. M.; Golin, R.; Caixeta, F. C.; Sanches, L.; Caixeta, D. S.; Avaliação Quanti-Qualitativa do Ar Interior de Uma Biblioteca Pública do Município de Cuiabá-MT. E\&S - Engineering and Science, (2017), 6:1.

\section{Método de Sedimentação Espontânea e Impactação - Bactérias}

Segundo Osimani et al. (2016), os parâmetros microbiológicos mais comumente avaliadas em bioaerossol é a contagem de bactérias mesófilas, como um indicador de contaminação de origem humana e animal; e Eumycetes (bolores e leveduras) como um indicador ambiental, muitas vezes relacionados com a presença elevada de umidade e poeira, redução da ventilação e má qualidade do ar.

De acordo com Degobbi e Gambale (2008), existem vários métodos que quantificam a biomassa total de fungos e bactérias, sendo que não existe nenhuma metodologia ótima para todas as situações, assim, o condutor do experimento deve ser treinado de maneira eficiente de tal forma a escolher o método mais satisfatório para análise dos resultados.

A Tabela 2 mostra os valores obtidos durante as coletas realizadas em quatro meses, pelo método de sedimentação espontânea, correspondente a cada ponto amostrado.

Tabela 2- Valores obtidos na contagem de UFC $/ \mathrm{m}^{3}$ pelo método de sedimentação espontânea.

\begin{tabular}{ccccc}
\hline $\begin{array}{c}\text { Pontos de } \\
\text { Coleta }\end{array}$ & Abril & Maio & Junho & Julho \\
\hline Piso 1: P1 & $9,6 \times 10^{1}$ & $3,4 \times 10^{1}$ & $6,8 \times 10^{1}$ & $4,1 \times 10^{1}$ \\
Piso 2: P2 & $6,8 \times 10^{1}$ & $1,5 \times 10^{2}$ & $2,7 \times 10^{1}$ & $1,3 \times 10^{1}$ \\
Piso 2: P3 & $1,0 \times 10^{2}$ & $4,1 \times 10^{1}$ & 0 & $6,8 \times 10^{1}$ \\
Piso 3: P4 & $1,1 \times 10^{2}$ & $1,3 \times 10^{1}$ & $2,0 \times 10^{1}$ & $3,4 \times 10^{1}$ \\
Piso 3: P5 & $7,6 \times 10^{1}$ & 0 & $6,1 \times 10^{1}$ & $6,1 \times 10^{1}$ \\
Piso 3: P6 & $1,4 \times 10^{1}$ & 0 & 0 & $3,4 \times 10^{1}$ \\
Piso 3: P7 & $6,8 \times 10^{1}$ & $4,7 \times 10^{1}$ & $1,3 \times 10^{1}$ & $4,7 \times 10^{1}$ \\
Piso 2: P8 & $3,4 \times 10^{1}$ & $2,0 \times 10^{1}$ & $2,0 \times 10^{1}$ & $6,8 \times 10^{1}$ \\
Piso 2: P9 & 0 & $4,1 \times 10^{1}$ & 0 & $1,3 \times 10^{1}$ \\
\hline
\end{tabular}

A Tabela 3 mostra os valores obtidos na contagem de bactérias durante a coleta realizada nos meses de Junho e Julho, pelo método de impactação.

Tabela 3- Valores obtidos na contagem de UFC/m³ pelo método de impactação.

\begin{tabular}{lll}
\hline $\begin{array}{c}\text { Pontos de } \\
\text { Coleta }\end{array}$ & Junho & Julho \\
\hline Piso 1: P1 & $1,4 \times 10^{1}$ & $2,4 \times 10^{1}$ \\
Piso 2: P2 & $8,4 \times 10^{1}$ & $2,6 \times 10^{1}$ \\
Piso 2: P3 & $1,8 \times 10^{1}$ & $2,9 \times 10^{1}$ \\
Piso 3: P4 & $3,0 \times 10^{1}$ & $1,0 \times 10^{1}$ \\
Piso 3: P5 & $2,1 \times 10^{1}$ & $2,9 \times 10^{1}$ \\
Piso 3: P6 & $4,2 \times 10^{1}$ & $8,3 \times 10^{1}$ \\
Piso 3: P7 & $8,0 \times 10^{1}$ & $4,4 \times 10^{1}$ \\
Piso 2: P8 & $2,5 \times 10^{1}$ & $1,2 \times 10^{1}$ \\
Piso 2: P9 & $1,4 \times 10^{1}$ & $2,6 \times 10^{1}$ \\
Externo & $6,3 \times 10^{1}$ & $1,3 \times 10^{1}$ \\
\hline
\end{tabular}

As recomendações da RE/ANVISA $n^{\circ} 9$ de 2003 refere aos agentes bacterianos como possível fonte de poluentes biológicos, mas não apresenta parâmetros de valor máximo recomendável. Em contrapartida o Decreto-Lei 79/2006 do Parlamento Europeu e do Conselho, define os valores máximos admissíveis para o parâmetro bacteriológico de 500 $\mathrm{UFC} / \mathrm{m}^{3}$

Considerando os valores mostrados nas tabelas supracitadas, pode-se inserir que a análise bacteriológica do ar interno da Biblioteca encontra-se dentro dos padrões aceitáveis, para ambas metodologias utilizadas. 
No método de sedimentação espontânea pode-se observar que não houve crescimento bacteriológico no mês de junho, em três pontos amostrais, P3, P6 e P9, enquanto que no método de impactação houve crescimento em todos os pontos amostrados. A baixa concentração de bactérias pode estar relacionada a limpeza dos aparelhos de ar condicionado, um dia anterior a coleta, a baixa densidade de pessoas e o design das áreas amostradas.

Estudo realizado por Caixeta et al. (2016) corroboram com os valores encontrados nessa pesquisa, onde o índice de bactérias na biblioteca de uma escola pública do município de Cuiabá apresentou-se abaixo do estabelecido no Decreto-Lei 79/2006.

Hayleeyesus e Manaye (2014) realizaram pesquisa em 8 bibliotecas da Universidade Jimma, os resultados revelaram altas concentrações de bactérias na biblioteca Ciência da Saúde e baixas concentrações na Biblioteca de Tecnologia da Ketofurdessa, sendo os gêneros mais isolados Micrococcus, Staphylococcus and Streptococcus, enquanto os menos isolados Bacillus e Neisseria. Mentese et al. (2009) realizaram estudos da concentração de bioaerossóis em nove bibliotecas na Túrquia, sendo os valores encontrados nesses ambientes em média de $1,13 \times 10^{2} \mathrm{UFC} / \mathrm{m}^{3}$.

Quanto aos resultados obtidos pela coloração de Gram, foi constatado que para ambas as metodologias utilizadas, 97\% das bactérias eram Gram positivas e apenas 3\% Gram negativas. Esses resultados sugerem que a contaminação bacteriana, suspensas no ar interior deriva da presença humana, uma vez que bactérias Gram positiva, inclusive cocos, pertencente à microflora saprófita, geralmente associada à pele humana e mucosa (HAYLEEYESUS e MANAYE, 2014).

Karbowska-Berent et al. (2011), isolaram um total de 36 espécies de bactérias em 18 gêneros, sendo o grupo dominante cocos Gram-positivos (64,1\% em média), com os gêneros Staphylococcus (S. chromogenes, S. simulans, S. epidermidis, S. sciuri - 39,5\% no total), e Micrococcus $(21,4 \%)$.

\section{Método de Impactação e Sedimentação Espontânea - Fungos}

AsTabelas4e 5mostram os valores obtidos para fungos utilizando-se o método de sedimentação espontânea e método de impactação, respectivamente.

Tabela 4 - Valores obtidos na contagem de UFC/m³ pelo método de sedimentação espontânea para fungos nos meses investigados.

\begin{tabular}{ccccc}
\hline $\begin{array}{c}\text { Pontos de } \\
\text { Coleta }\end{array}$ & Abril & Maio & Junho & Julho \\
\hline Piso 1: P1 & $4,8 \times 10^{1}$ & $6,8 \times 10^{1}$ & $1,4 \times 10^{1}$ & $1,4 \times 10^{1}$ \\
Piso 2: P2 & $5,5 \times 10^{1}$ & $2,1 \times 10^{1}$ & $6,8 \times 10^{1}$ & $6,8 \times 10^{1}$ \\
Piso 2: P3 & $1,4 \times 10^{1}$ & $2,1 \times 10^{1}$ & $6,8 \times 10^{1}$ & $6,8 \times 10^{1}$ \\
Piso 3: P4 & $6,8 \times 10^{1}$ & $6,8 \times 10^{1}$ & $6,8 \times 10^{1}$ & $6,8 \times 10^{1}$ \\
Piso 3: P5 & $5,5 \times 10^{1}$ & $2,1 \times 10^{1}$ & $1,4 \times 10^{1}$ & $1,4 \times 10^{1}$ \\
Piso 3: P6 & $6,2 \times 10^{1}$ & $1,4 \times 10^{1}$ & $1,4 \times 10^{1}$ & $1,4 \times 10^{1}$ \\
Piso 3: P7 & $2,1 \times 10^{1}$ & $2,1 \times 10^{1}$ & $2,1 \times 10^{1}$ & $2,1 \times 10^{1}$ \\
Piso 2: P8 & $4,1 \times 10^{1}$ & $1,4 \times 10^{1}$ & $2,7 \times 10^{1}$ & $2,7 \times 10^{1}$ \\
Piso 2: P9 & $4,8 \times 10^{1}$ & $2,1 \times 10^{1}$ & $2,1 \times 10^{1}$ & $2,1 \times 10^{1}$ \\
\hline
\end{tabular}


Campos, F. M.; Golin, R.; Caixeta, F. C.; Sanches, L.; Caixeta, D. S.; Avaliação Quanti-Qualitativa do Ar Interior de Uma Biblioteca Pública do Município de Cuiabá-MT. E\&S - Engineering and Science, (2017), 6:1.

Tabela 5- Valores obtidos na contagem de UFC/ $\mathrm{m}^{3}$ pelo método de impactação em meio sólido para fungos e a relação I/E nos meses investigados.

\begin{tabular}{lcccc}
\hline $\begin{array}{c}\text { Pontos de } \\
\text { Coleta }\end{array}$ & Junho & Julho & $\begin{array}{c}\text { I/E } \leq \mathbf{1 , 5} \\
\text { Junho }\end{array}$ & $\begin{array}{c}\text { I/E } \leq \mathbf{1 , 5} \\
\text { Julho }\end{array}$ \\
\hline Piso 1: P1 & $6,4 \times 10^{1}$ & $1,5 \times 10^{1}$ & 1,73 & 1,25 \\
Piso 2: P2 & $5,4 \times 10^{1}$ & $2,1 \times 10^{2}$ & 1,45 & 1,75 \\
Piso 2: 3 & $8,1 \times 10^{1}$ & $3,2 \times 10^{1}$ & 2,18 & 2,66 \\
Piso 3: P4 & $6,4 \times 10^{1}$ & $8,4 \times 10^{1}$ & 1,72 & 7 \\
Piso 3: P5 & $4,4 \times 10^{1}$ & $1,6 \times 10^{1}$ & 1,18 & 1,33 \\
Piso 3: P6 & $9,3 \times 10^{1}$ & $9,3 \times 10^{1}$ & 2,51 & 7,75 \\
Piso 3: P7 & $4,3 \times 10^{1}$ & $6,4 \times 10^{1}$ & 1,16 & 5,33 \\
Piso 2: P8 & $9,8 \times 10^{1}$ & $7,6 \times 10^{1}$ & 2,64 & 6,33 \\
Piso 2: P9 & $3,0 \times 10^{1}$ & $3,8 \times 10^{1}$ & 0,81 & 3,16 \\
Externo & $3,7 \times 10^{1}$ & $1,2 \times 10^{1}$ & & \\
\hline
\end{tabular}

Considerando os valores estabelecidos pela RE/ANVISA n ${ }^{\circ} 9$ de 2003 , em que o Valor Máximo Recomendável - VMR, para contaminação microbiológica deve ser $\leq 750 \mathrm{UFC} / \mathrm{m}^{3}$ de fungos, para a relação $\mathrm{I} / \mathrm{E} \leq 1,5$, onde I é a quantidade de fungos no ambiente interior e $\mathrm{E}$ é a quantidade de fungos no ambiente exterior, nota-se que para ambas as metodologias utilizadas, os valores encontrados para fungos estão abaixo do recomendado (Tabelas 4 e 5).

Por outro lado, no quesito relação interior/exterior, no método de impactação, nos meses de junho e julho a maior relação foi no P8 $(2,64)$ e P6 $(7,75)$, respectivamente. Os índices $\leq 1,5$ foram encontrados nos pontos P2 $(1,45)$, P5 $(1,18)$, P7 $(1,16)$ e P9 $(0,81)$ para o mês de junho, enquanto que no mês de julho apenas nos pontos P1 $(1,25)$ e P5 $(1,33)$ (Tabelas 4 e 5). De acordo com a RE/ANVISA $n^{\circ} 9$ de 2003 , quando a relação I/E encontrada for superior ao estabelecido, se faz necessário um diagnóstico de fontes para intervenção corretiva.

Segundo Hayleeyesus e Manaye (2014), uma série de fatores, tais como temperatura, umidade, má ventilação, estruturas de construção e localização, condições de higiene e outros, favorecem o crescimento e multiplicação de microrganismos. Outrossim, Micheluz et al. (2015), afirmam que estas condições acabam por ser adequado para o desenvolvimento e crescimento de vários fungos e bactérias.

Clark et al. (2004) mencionam que a umidade é a principal condição de desenvolvimento de fungos, sendo de forma geral o crescimento ótimo com umidade relativa do ar acima de $95 \%$ e inibido em umidade relativa abaixo de $50 \%$. Ademais, KarbowskaBerent et al. (2011) mencionam que se a ventilação das bibliotecas não for adequada, o número de fungos pode aumentar, em decorrência da dispersão de esporos depositados em várias fontes internas, tais como livros contaminados, paredes, superfícies de materiais, solo e outros.

Segundo Lacaz et al. (2002), no Brasil, de maneira geral, nos períodos de outono e inverno, há maior incidência de fungos, sendo os gêneros mais frequentemente detectados Cladosporium, Penicillium, Aspergillus, Curvularia, Rhizopus, Helminthosporium, Trichoderma, Fusarium, Candida, Aureobasidium, Rhodotorula.

Neste estudo foram isolados diferentes gêneros fúngicos, no entanto foram selecionados apenas osgêneros Aspergillussp e Penicillium sp. Pelo método de sedimentação espontânea pode-se observar na Tabela 6 , que na soma de todos os meses de coleta, no ponto P1 foram isoladas 23 colônias fúngicas distintas, sendo destas 39,13\% de Aspergillussp. e 4,34\% de Penicilliumsp, enquanto que nos pontos P4, P5 e P9 não foi encontrada a presença desses gêneros. Salienta-se que os gêneros $A$ spergillussp. e Penicillium sp. foram encontrados em maiores porcentagens nos pontos P7 $(80 \%)$ e P8 $(36,84)$, respectivamente. 
Por outro lado, no método de impactação, o ponto P2 apresentou maior quantidade de isolados fúngicos, perfazendo um total de 60 colônias, sendo destas 86,66\% do gênero Aspergillussp. e apenas 5\% Penicillium sp. A maior quantidade de isolados de Penicilliumsp. ocorreu no ponto P9 (80\%) (Tabela 7).

Tabela 1-Ambientes da Biblioteca Central, número de UFC isoladas por ponto e seus respectivos gêneros, método de sedimentação espontânea.

\begin{tabular}{|c|c|c|c|c|}
\hline $\begin{array}{l}\text { Pontos de } \\
\text { Coleta }\end{array}$ & $\begin{array}{l}\text { Total isolados } \\
\mathrm{UFC} / \mathrm{m}^{3}\end{array}$ & Gêneros & $\mathrm{UFC} / \mathrm{m}^{3}$ & $(\%)$ \\
\hline \multirow[t]{2}{*}{ Piso 1: P1 } & 23 & Aspergillussp. & 9 & 39,13 \\
\hline & & Penicillimsp. & 1 & 4,34 \\
\hline \multirow[t]{2}{*}{ Piso 2: P2 } & 10 & Aspergillussp. & 2 & 20 \\
\hline & & Penicillimsp. & 0 & 0 \\
\hline \multirow[t]{2}{*}{ Piso 2: P3 } & 12 & Aspergillussp. & 6 & 50 \\
\hline & & Penicillimsp. & 1 & 8,33 \\
\hline \multirow[t]{2}{*}{ Piso 3: P4 } & 3 & Aspergillussp. & 0 & 0 \\
\hline & & Penicillimsp. & 0 & 0 \\
\hline \multirow[t]{2}{*}{ Piso 3: P5 } & 5 & Aspergillussp. & 0 & 0 \\
\hline & & Penicillimsp. & 0 & 0 \\
\hline \multirow[t]{2}{*}{ Piso 3: P6 } & 8 & Aspergillussp. & 1 & 12,5 \\
\hline & & Penicillimsp. & 0 & 0 \\
\hline \multirow[t]{2}{*}{ Piso 3: P7 } & 10 & Aspergillussp. & 8 & 80 \\
\hline & & Penicillimsp. & 0 & 0 \\
\hline \multirow[t]{2}{*}{ Piso 2: P8 } & 19 & Aspergillussp. & 11 & 57,89 \\
\hline & & Penicillimsp. & 7 & 36,84 \\
\hline \multirow[t]{2}{*}{ Piso 2: P9 } & 7 & Aspergillussp. & 0 & 0 \\
\hline & & Penicillimsp. & 0 & 0 \\
\hline
\end{tabular}

Tabela 2-Ambientes da Biblioteca Central, número de UFC isoladas por ponto e seus respectivos gêneros, método de impactação.

\begin{tabular}{|c|c|c|c|c|}
\hline $\begin{array}{l}\text { Pontos de } \\
\text { Coleta }\end{array}$ & $\begin{array}{l}\text { Total de } \\
\text { isolados } \\
\mathrm{UFC} / \mathrm{m}^{3}\end{array}$ & Gêneros & $\mathrm{UFC} / \mathrm{m}^{3}$ & $(\%)$ \\
\hline \multirow[t]{2}{*}{ Piso 1: P1 } & 2 & Aspergillussp. & 1 & 50 \\
\hline & & Penicillimsp. & 0 & 0 \\
\hline \multirow[t]{2}{*}{ Piso 2: P2 } & 60 & Aspergillussp. & 52 & 86,66 \\
\hline & & Penicillimsp. & 3 & 5 \\
\hline \multirow[t]{2}{*}{ Piso 2: P3 } & 12 & Aspergillussp. & 7 & 58,33 \\
\hline & & Penicillimsp. & 3 & 25 \\
\hline \multirow[t]{2}{*}{ Piso 3: P4 } & 5 & Aspergillussp. & 0 & 0 \\
\hline & & Penicillimsp. & 3 & 60 \\
\hline \multirow{2}{*}{ Piso 3: P5 } & 0 & Aspergillussp. & 0 & 0 \\
\hline & & Penicillimsp. & 0 & 0 \\
\hline \multirow[t]{2}{*}{ Piso 3: P6 } & 25 & Aspergillussp. & 7 & 28 \\
\hline & & Penicillimsp. & 17 & 68 \\
\hline \multirow[t]{2}{*}{ Piso 3: P7 } & 45 & Aspergillussp. & 1 & 2,22 \\
\hline & & Penicillimsp. & 30 & 66,66 \\
\hline \multirow[t]{2}{*}{ Piso 2: P8 } & 17 & Aspergillussp. & 3 & 17,64 \\
\hline & & Penicillimsp. & 12 & 70,58 \\
\hline \multirow[t]{2}{*}{ Piso 2: P9 } & 15 & Aspergillussp. & 2 & 13,33 \\
\hline & & Penicillimsp. & 12 & 80 \\
\hline
\end{tabular}

A representativa variedade de fungos encontrada nesse estudo, assemelham-se a resultados obtidos por outros autores. Estudo realizado por Menezes et.al. (2006) em uma Biblioteca de uma Universidade Federal do Ceará, isolaram predominantemente os gêneros Aspergillussp., Penicilliumsp., Alternaria sp., Curvularia sp.eCladosporiumsp. Estudo 
Campos, F. M.; Golin, R.; Caixeta, F. C.; Sanches, L.; Caixeta, D. S.; Avaliação Quanti-Qualitativa do Ar Interior de Uma Biblioteca Pública do Município de Cuiabá-MT. E\&S - Engineering and Science, (2017), 6:1.

realizado por Micheluz et al. (2015) na Biblioteca de uma Universidade Italiana, identificaram oito espécies fúngicas, dentro de quatro gêneros, sendo as espécies mais frequentemente encontradas Aspergilluscreber e Penicilliumbrevicompactum.

Degobbi e Gambale (2008) citam que em termos nacionais, de acordo com os trabalhos realizados e disponíveis na literatura, Penicilliumsp. não é necessariamente o mais prevalente em ambientes interiores no Brasil. Além disso, esses fungos não tem significado expressivo como agentes causadores de asma no Brasil, ao contrário do verificado nos Estados Unidos.

Em contrapartida, Aspergillussp. vem adquirindo especial atenção nesse âmbito, pois é um fungo que pode ser encontrado em todos os ambientes e o ar é uma importante via de dispersão de seus propágulos e consequentemente, de transmissão para pacientes. Devido ao pequeno tamanho do conídio, este pode ficar em suspensão no ar por longos períodos de tempo e permanecer viável por meses, mesmo em locais com pouca umidade (WARRIS et al. (2001). A aspergilose invasiva apresenta-se como importante causa de mortalidade entre pacientes neutropênicos, principalmente aqueles com leucemia e que receberam transplantes de órgãos, sendo que70\% das infecções fúngicas não causadas por Candidasp. são causadas por Aspergillus, em especial Aspergillus fumigatus (Morrison 2001).

\section{CONCLUSÕES}

Em suma, os resultados obtidos na contagem bacteriana não apresentaram limites superiores a $500 \mathrm{UFC} / \mathrm{m}^{3}$. Todavia, pelo teste de coloração de Gram foi constatado que $97 \%$ das bactérias eram Gram positivas, tal ocorrência pode estar relacionada ao fato de que estas bactérias podem habitar na pele do homem, sendo este contribuinte para o transporte de microrganismos.

A contagem fúngica também não excedeu o valor máximo estabelecido pela legislação vigente, de $\geq 750 \mathrm{UFC} / \mathrm{m}^{3}$, por outro lado, a relação $\mathrm{I} / \mathrm{E}$ em vários pontos amostrados, apresentou valores superiores ao indicado, sugerindo um diagnóstico de fontes para intervenção corretiva. Dentre os diversos gêneros isolados, apenas os gêneros Aspergillussp. E Penicillium sp. foram identificados.

Consoante, aos resultados obtidos para temperatura e umidade, na maioria dos pontos amostrados e período de coleta, não estão de acordo com a resolução vigente.

Tais resultados sugerem que em locais de aprendizagem e desenvolvimento intelectual, social e pessoal como a biblioteca, a necessidade da implantação de medidas de prevenção e proteção de todos os seus frequentadores no que se refere à problemática da QAI.

\section{REFERÊNCIAS}

ANVISA - Agência Nacional de Vigilância Sanitária. Resolução nº9 de 16 de janeiro de 2003. Diário Oficial da União, Brasília, DF, 20 janeiro de 2003.

CAIXETA,D. S.;SILVA, T. A.;SANTANA, F. M. F.;ALMEIDA, W. T. P.. Monitoramento da Qualidade do Ar Interior de uma Escola da Rede Pública Localizada no Município de Cuiabá-MT. Engineering and Science, 5 (1): 20-28. doi: 10.18607/ES20165047.2006.

CLARK, M. N.; AMMANN, H. M.; BRUNEKREEF, B.; EGGLESTON, B.; FISK, W. J.; FULLILOVE, R. E.; GUERNSEY, J.; NEVALAINEN, A.; VON ESSEN, S.G. Damp Indoor Spaces and Health, Institute of Medicine of the National Academies, Washington DC. 2004. 
Campos, F. M.; Golin, R.; Caixeta, F. C.; Sanches, L.; Caixeta, D. S.; Avaliação Quanti-Qualitativa do Ar Interior de Uma Biblioteca Pública do Município de Cuiabá-MT. E\&S - Engineering and Science, (2017), 6:1.

DEGOBBI, M. C.; GAMBALE, W. (2008). Síndrome dos edifícios doentes: aspectos microbiológicos, qualidade do ar em ambientes interiores e legislação brasileira. Encarte Técnico Revista ABRAVA, 261.

Friberg B, Friberg S, Burman LG (1999) Inconsistent Correlation between aerobic bacterial surface and air counts in operating rooms with ultra clean laminar air flows: proposal of a new bacteriological standard for surface contamination. The Journal of Hospital Infection, 42: 287-293. doi:10.1053/jhin.1998.0598

GAMBALE,W.; CROCE, J.; MANSO ERC, CROCE M, SALES JM (1993) Library fungi at University of São Paulo and their relationship with respiratory allergies. Journal of Investigative Allergology and Clinical Immunology, 3: 45-50.

HAYLEEYESUS,S. F, MANAYE,A. M.(2014) Microbiological Quality of Indoor Air in University Libraries. Asian Pacific Journal of Tropical Biomedicine,4: 312317.doi:10.12980/APJTB.4.2014C807

KARBOWSKA-BERENT,J.; GÓRNY,R. L.;STRZELCZYK,A. B.;WLAZŁO,A.(2011) Airborne and dust borne microorganisms in selected Polish libraries and archives. Building and Environment, 46 (10): 1872-1879. doi.org/10.1016/j.buildenv.2011.03.007

LACAZ, C. S. PORTO, E.; MARTINS,J.E.C.; HEINS-VACCARI,E.M.; MELO, N.T.de Tratado de micologia médica. São Paulo: Savier, 2002.

Mendes A', Bonass S, Aguiar L, Pereira C, Neves P, Silva S, Mendes D, Guimarães L, Moron R, Teixeira JP (2015) Indoor air quality and the rmal comfort in elderly care centers. New Sensing Technologies and Methods for Air Pollution Monitoring, 14 (3): 486-501. http://dx.doi.org/10.1016/j.uclim.2014.07.005

Mentese S, Arisoy M, Rad AY, Gullu G (2009). Bacteria and fungi levels in various indoor and outdoor environments in Ankara, Turkey Clean,37 (6): 487-493.

MINISTÉRIO DAS OBRAS PÚBLICAS, TRANSPORTES E COMUNICAÇÕES (2006). Decreto-Lei no 79 de 4 de Abril de 2006. Diário da República, 4 de Abril de 2006.

MIBAC, (2001). Atto d'indirizzo sui critério tecnico-scientifici e sugli standard difunzionamento e sviluppo dei musei, D.Lgs, 112 (98) .

Menezes EA, Alcanfor AC, Cunha FA (2006). Fungos anemófilos na sala de periódicos da biblioteca de ciências da saúde da Universidade Federal do Ceará. RBAC, 38 (3): 155-158, 2006.

Micheluz A, Manente S, Tigini V, Prigione V, Pinzari F, Ravagnan G, Varese GC (2015). The extreme environment of a library: xerophilic fungi inhabiting indoor niches. International Biodeterioration \& Biodegradation, 99: 1-7. doi.org/10.1016/j.ibiod.2014.12.012

MORRISON, V. A., Infections in patients with chronic lymphocytic leukemia. In: Cheson BD, editor. Chronic lymphoid Leukemias. 2 ed. New York: Marcel Dekker, 2001. 
Osimani A, Garofalo C, Milanovic V, Taccari M, Aquilanti L, Polverigiani S, Clementi F (2016) Indoor air quality in mass catering plants: occurrence of airborne eumycetes in a university canteen. International Journal of Hospitality Management, 59: 110.doi.org/10.1016/j.ijhm.2016.08.004

Pantoja LDM, Rizzo RS, Carvalho BS, Ferreira V C, Galasv KS, Fonseca FRM, Paixão GC (2012) Constituição da micobiota aérea de bibliotecas públicas no município de Fortaleza, Estado do Ceará, Brasil. Revista Eletrônica de Biblioteconomia e Ciência da Informação, 17 (34): 31-41. doi: 10.5007/1518-2924.2012v17

Schirmer Wn, Pian, L B, Szymanski Mse, Gauer MA (2011) A poluição do ar em ambientes internos e a síndrome dos edifícios doentes. Ciência e saúde coletiva, 16 (8): 3583-3590. doi.org/10.1590/S1413-81232011000900026

Silva Filho, J. T. Manual de Conservação de Acervos Bibliográficos da UFRJ. Rio de Janeiro: Universidade Federal do Rio de Janeiro. Sistema de Bibliotecas e Informação - UFRJ /SiBI, 2004.

Skóra J, Gutarowska B, Pielech-Przybylska K, Ste,pien' L, Pietrzak K, Piotrowska M, Pietrowski P (2015) Assessment of microbiological contamination in the work environments of museums, archives and libraries. Aerobiologia, 31: 389-401. Doi 10.1007/s10453-015$9372-8$

Warris A, Voss A, Verwij PE (2001). Hospital sources of Aspergillus species: new routes of transmission?. Revistal bero americana de Micologia. 18:156-62. 